\title{
GIS IN ARMY: USAGE OF GIS IN SHOOTING WITH WEAPON IN PURPOSE TO MINIMIZE RESOURCES AND MAXIMIZE THE RESULTS
}

DOI: http://dx.doi.org/10.18509/GBP.2017.15

UDC: 528:004]:623.6.09

\author{
Aleksandar Petrovski \\ Dimitar Bogatinov \\ Dime Boshkovski
}

University „Goce Delchev“ Shtip, Military academy „General Mihailo Apostolski“, Macedonia

\begin{abstract}
The right information and the use of advanced technologies are big lifesaving tool on the battlefield. If commanders and commandants have right information for their enemy (position, number, equipment etc) they can make better decisions respectively which weapon to use, how much soldiers to send to finished the task, which one position will be the most effective in executing the target, which soldier to select to finish the mission.

In this paper we purpose an application and modules where with the knowledge of our position and enemy position and result that our soldiers had had in the past, the Tactical operational center will make the best decision of which soldier and weapon will be used on the battlefield in order to finish the mission with minimum direct shots.
\end{abstract}

Keywords: GIS, army, decision, battlefield, data.

\section{INTRODUCTION}

Most of security decisions connected with national involve geography - whether it's strategic intelligence determination of terrorist intent, a war fighting command decision about how to strike the enemy, or a base management decision about how to site a new building with minimal impact. GIS technology plays a critical role in modern defense and intelligence systems as an increasingly omnipresent spatial information and application infrastructure.

Operations have become more and more complex due to the use of different platforms, sensors, and systems during the missions. Our forces and our allies need to tailor their battle management systems to integrate data from a variety of platforms and sensors, offering customers the tactical clarity and confidence essential to operational success. These systems also need to deal with command and control, communications and information management problems. A modular software approach needs to deliver secure, reliable communications for network-centric operations at every tier. For holistic battlefield management, our application need to provides all the tools needed to support planning and execution of operations, including terrain analysis, route management and global distribution of tactical and operational information.[1] Our tactical battle management software and systems integration capabilities help military forces digitize their operations, providing a continuous, real-time platform for situational awareness and staff functions, including hostile and blue force tracking, radio communications, 
planning, personnel, intelligence, local weather and other data to provide an edge on the battlefield.

One of the first tasks is gathering specific information about objects, buildings and devices on the battlefield through geo-location and plots field data. Buildings and streets are the new battlefields in which every corner hides different type of danger. Soldiers have a very difficult task, to observe and save themselves from the various attacks. With the geo-location data, we know the position of our and enemy forces. Having this information in real-time we can make better decision of which soldier and weapon we will use on the battlefield to finish the mission with minimum direct shots and minimum risk.

We have created two possible modules that will send the gathered GIS battlefield data into the Tactical operational center (TOC). The created algorithms than will process the data and in accordance to the results the commanding officer will authorize execution of enemy targets based on soldiers and target position and results during the training missions.

\section{MODULE ARHITECTURE}

\section{Position determination modules}

For the architecture of this model we have created two possible modules use to determine the coordinates of the soldiers and the target.

The first model named $\boldsymbol{U A V}$ model is simple and it will be used as a primary module. It uses UAV to determine the location of the target and the position of the soldiers.[2] After the UAV gathers the coordinates they are send in 10 seconds interval the TOC and the data is imputed to algorithm that we will describe in following chapter [3]. When the algorithm finish with the calculation the commanding officer gives an executive order to the soldier to destroy the target in line with the output of the algorithm.

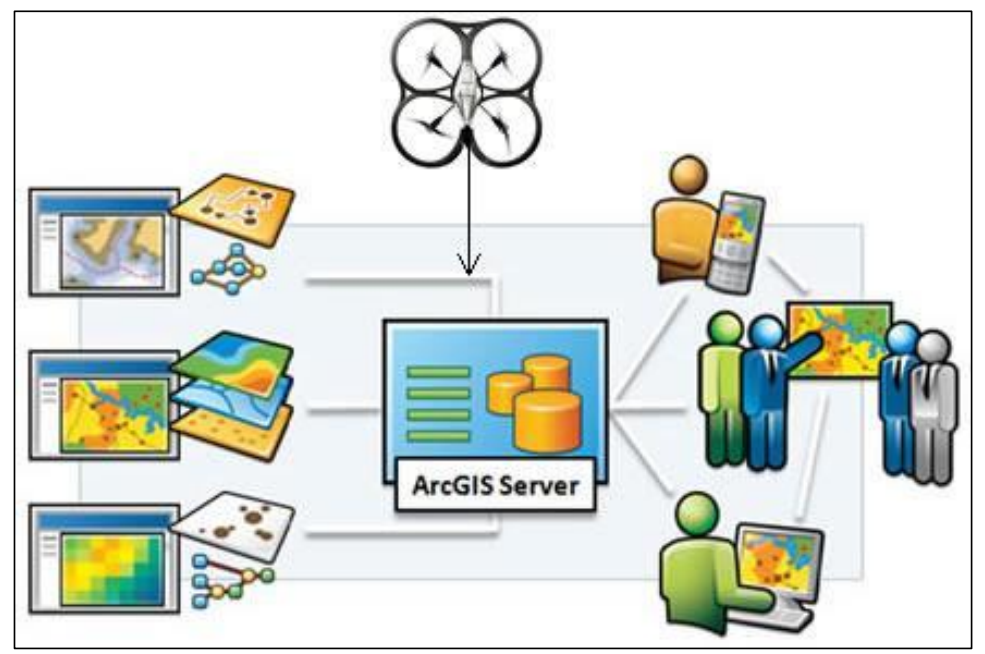

Figure 1: GIS Cloud mapping with UAV [6]

The second model named distance model is more complex and its without UAV, the position of the soldier is send via the VHF military radio from the built-in GPS. The distance and the angle to the target is determinate by the two team members using Laser Rangefinder and send to the TOC using voice communication [4]. There will be addition to the algorithm that will calculate the coordinates of the target using the coordinated of 
the soldiers, and the known distance to the target. This is done using simple geometry to determine third point when two points and all sides (distance) are known [5]. and is calculating the coordinated of the target and send them as an input to the algorithm with the received GPS data from the radios. The following steps are same as the UAV model. System architecture of this model is represented in the following figure. Two team members use standard radio and laser rangefinder, and then the data is send via land mobile radio, to the team leader, and forwarded via Harris RF7800M and VHF Radio network to the TOC where the algorithm calculates the coordinate of the target and makes the decision in accordance to the created algorithm.

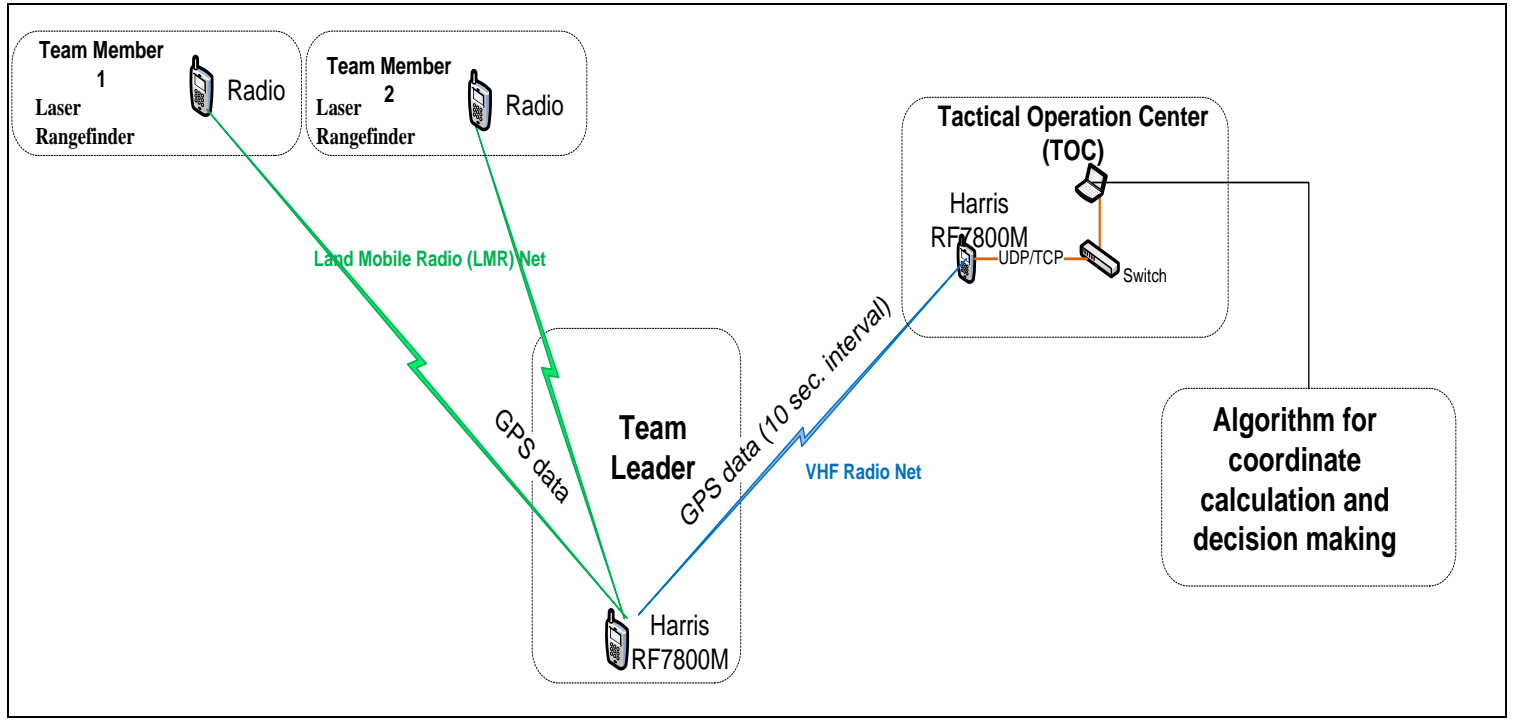

Figure 2. System architecture for the distance model

\section{ALGORITHM}

Steps of the algorithm:

First: for all our soldiers we are checking the visibility to the goal by our GIS connected by UAV orvoice communication.

Second for soldiers that have visibility we measure the distance to the goal.

Third we get the information for weather conditionsfrom nearby weather stations or our meteoritical data.

Fourth from the appropriate tables we get the appropriate probabilities to hit the goal.

Fifth (and finally) the soldier with the biggest probability to hit the goal gets an order to execute the target.

\section{EXPLAINING ONE REAL SITUATION ON THE GROUND}

We are giving real description of our algorithm. We have five soldiers and for them we know the number of hits to the goal from 1000 attempts. Also we have number of hits in different weather condition: sun weather, haze weather, poor rain, and straight rain. Another important characteristic that we must to now is distance from the soldier to the goal.

Table 1. Sun weather

\begin{tabular}{|l|l|l|l|}
\hline \multicolumn{4}{|c|}{ SUN WEATHER } \\
\hline Soldier 1 & 1000 hits & 600 meters & 0,93 goal \\
\hline Soldier 2 & 1000 hits & 800 meters & 0,749 goal \\
\hline
\end{tabular}


Cartography, GIS and Spatial Planning, Teaching and educational geography

\begin{tabular}{|l|l|l|l|}
\hline Soldier 3 & 1000 hits & 800 meters & 0,89 goal \\
\hline Soldier 4 & 1000 hits & 800 meters & 0,91 goal \\
\hline Soldier 5 & 1000 hits & 500 meters & 0,98 goal \\
\hline
\end{tabular}

Table 2. Haze weather

\begin{tabular}{|l|l|l|l|}
\hline \multicolumn{4}{|c|}{ HAZE WEATHER } \\
\hline Soldier 1 & 1000 hits & 600 meters & 0,793 goal \\
\hline Soldier 2 & 1000 hits & 800 meters & 0,65 goal \\
\hline Soldier 3 & 1000 hits & 800 meters & 0,79 goal \\
\hline Soldier 4 & 1000 hits & 800 meters & 0,79 goal \\
\hline Soldier 5 & 1000 hits & 500 meters & 0,86 goal \\
\hline
\end{tabular}

Table 3. Poor rain weather

\begin{tabular}{|l|l|l|l|}
\hline \multicolumn{4}{|c|}{ POOR RAIN WEATHER } \\
\hline Soldier 1 & 1000 hits & 600 meters & 0,80 goal \\
\hline Soldier 2 & 1000 hits & 800 meters & 0,82 goal \\
\hline Soldier 3 & 1000 hits & 800 meters & 0,89 goal \\
\hline Soldier 4 & 1000 hits & 800 meters & 0,85 goal \\
\hline Soldier 5 & 1000 hits & 500 meters & 0,73 goal \\
\hline
\end{tabular}

Table 4. Straight rain weather

\begin{tabular}{|l|l|l|l|}
\hline \multicolumn{4}{|c|}{ STRAIGHT RAIN WEATHER } \\
\hline Soldier 1 & 1000 hits & 600 meters & 0,39 goal \\
\hline Soldier 2 & 1000 hits & 800 meters & 0,41 goal \\
\hline Soldier 3 & 1000 hits & 800 meters & 0,31 goal \\
\hline Soldier 4 & 1000 hits & 800 meters & 0,55 goal \\
\hline Soldier 5 & 1000 hits & 500 meters & 0,54 goal \\
\hline
\end{tabular}

On the this picture we have example of one possible situation on the field. Our three (blue circle) and one enemy (red circle) soldiers are at the positions.

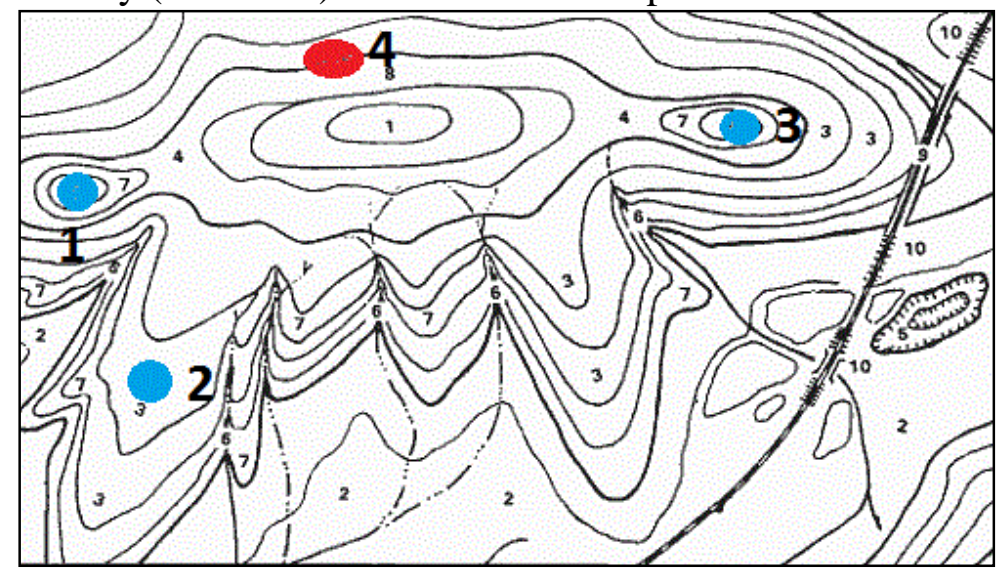

Figure 3. Real position on the field

ALGORITHM WORKFLOW

First: From the ground situation soldiers with number 1 and 3 have visibility to the goal. Second: The distance from soldier with number 1 to the goal is $600 \mathrm{~m}$ and the distance from soldier 3 to the goal is $800 \mathrm{~m}$.

Third: The soldiers from the field report us that the weather is sunny, and we are checking weather condition on android application. 
Fourth: From the tables, we can see that probability for soldier with number 1 is 0,93 and 0,89 for soldier with number 3 . This calculating will be automatically done by the application in our TOC center.

Fifth: Algorithm give us final result that soldier with number lis most suited to finish the task.

Six: The commanding officer gives the executive order.

\section{CONCLUSION}

Today we live in a time were the most important and power things are information. The Army is one of the affected areas where information is of critical importance. GIS has a fast growth in today world, but his capabilities are not explored completely. The possibilities that are offered from GIS have a wide range of use, and because of it, this information system nowadays is more and more used in various fields of study. Of course that military industry discovers different ways of composing this information system in manufacturing of new devices, vehicles and weapons and also in integrating of the GIS in the existing technologies.

We are using every modern equipment for solving every mission on different types of terrain and climate conditions supported by GIS on the web or softer [7]. This gives a chance for adopting this application on every terrain and any climate conditions with which means that it will be effective at every point where we have updated maps in GIS.

\section{REFERENCES:}

[1] Tortonesi M, Stefanelli C, Benvegnu E, Ford K, Suri N, Linderman M. Multiple-UAV coordination and communications in tactical edge networks. IEEE Communications Magazine. 2012 Oct 1;50(10):48-55.

[2] Achkoski J, Koceski S, Bogatinov D, Temelkovski B, Stevanovski G, Kocev I. Remote triage support algorithm based on fuzzy logic. Journal of the Royal Army Medical Corps. 2016 Jul 14:jramc-2015.

[3] Steinvall O, Persson R, Berglund F, Gustafsson OK, Gustafsson F. Using an eyesafe military laser range finder for atmospheric sensing. InSPIE Defense+ Security 2014 Jun 9 (pp. 90800W-90800W). International Society for Optics and Photonics.

[4] Farin G. Curves and surfaces for computer-aided geometric design: a practical guide. Elsevier; 2014 Jun 28.

[5] Charles M. Grinstead, J. Laurie Snell. Introduction to Probability. 520.

[6] Aleksandar Petrovski, Mihajlo Tosevski, Geobalcanica 2016, GIS IN ARMY: Application of gis in geo-reconnaissance and c4is in army purposes, DOI: http://dx.doi.org/10.18509/GBP.2016.21, UDC:004:528.85]:355.31(497.7),

proceedings Geobalcanica 2016.

[7] Aleksandar Petrovski, Simona Naumova, GIS IN CRISES MANAGEMENT: Use of smart phone gis application in the event of natural disaster in vital function of man in trouble. DOI: http://dx.doi.org/10.18509/GBP.2016.20,

UDC:004.774:528.85]:[614.8:35.077(497.7), proceedings Geobalcanica 2016. 